\title{
Avulsion fracture of the lesser trochanter: an unusual cause of hip pain in an adolescent
}

\author{
Eugenio Vazquez, MD; Tommy Y. Kim, MD; Timothy P. Young, MD
}

\section{ABSTRACT}

Sports injuries involving the hip and groin are common. Special consideration must be given to musculoskeletal injuries in children and adolescents as their immature skeletons have growth plates that are relatively weaker than the tendons and ossified bone to which they connect. We present a case of an adolescent athlete with acute-onset groin pain who was found to have an avulsion fracture of the lesser trochanter.

\section{RÉSUMÉ}

Les accidents du sport touchant la hanche et l'aine sont fréquents. II faut porter une attention particulière aux blessures musculosquelettiques chez les enfants et les adolescents étant donné que le squelette encore immature est constitué en partie de cartilages de conjugaison relativement plus faibles que les tendons et les pièces ossifiées qu'ils relient. Voici le cas d'un jeune athlète, à l'âge de I'adolescence, chez qui est apparue une douleur subite à l'aine et qui s'est avérée une fracture-avulsion du petit trochanter.

Keywords: adolescent, avulsion fracture, hip pain, lesser trochanter

A 15-year-old African-American male presented to the pediatric emergency department (ED) with a complaint of left hip pain. The pain began while sprinting during football practice on the previous day. He reported feeling a "pop" deep in his left hip. This was immediately followed by severe pain and an inability to bear weight on the left lower extremity. The patient reported that he fell to the ground and required assistance from his trainers to get off the field.
The patient was initially taken to another ED on the day of the injury, where he was evaluated and given the diagnosis of a muscular strain. No radiographs were obtained during that visit. He was prescribed an analgesic and a muscle relaxant and provided with crutches for ambulation.

Because of the severity and persistence of the pain, the patient was brought to our pediatric ED for reevaluation. We found that he was in no distress while at rest but avoided movement of his left lower extremity. His vital signs were stable. When examined in a supine position, the patient was noted to have pain on elevation of his left leg. Rotation of the leg while in full extension did not elicit significant pain. When the patient was examined in a sitting position (with hips flexed at a $90^{\circ}$ angle), pain was elicited with further flexion of the left hip, giving a positive Ludloff sign. The patient was noted to have an antalgic gait. A radiograph of the pelvis revealed an avulsion fracture of the apophysis of the left lesser trochanter (Figure 1). The orthopedic team was consulted and recommended non-weight bearing on the affected limb with crutches, analgesics, and clinic follow-up in 2 weeks.

\section{DISCUSSION}

Sports injuries involving the hip and groin resulting from sudden and forceful muscle contractions are common. ${ }^{1}$ Most of these injuries in skeletally mature patients represent soft tissue injuries such as musculotendinous strains. ${ }^{1}$ Pelvic and proximal femur fractures are seen less frequently in adult athletes as these injuries

From the Division of Pediatric Emergency Medicine, Department of Emergency Medicine, Loma Linda University Medical Center and Children's Hospital, Loma Linda, CA.

Correspondence to: Dr. Eugenio Vazquez, Division of Pediatric Emergency Medicine, Department of Emergency Medicine, A-108, Loma Linda University Medical Center and Children's Hospital, 11234 Anderson Street, Loma Linda, CA 92354; Evazquez@llu.edu.

This article has been peer reviewed. 


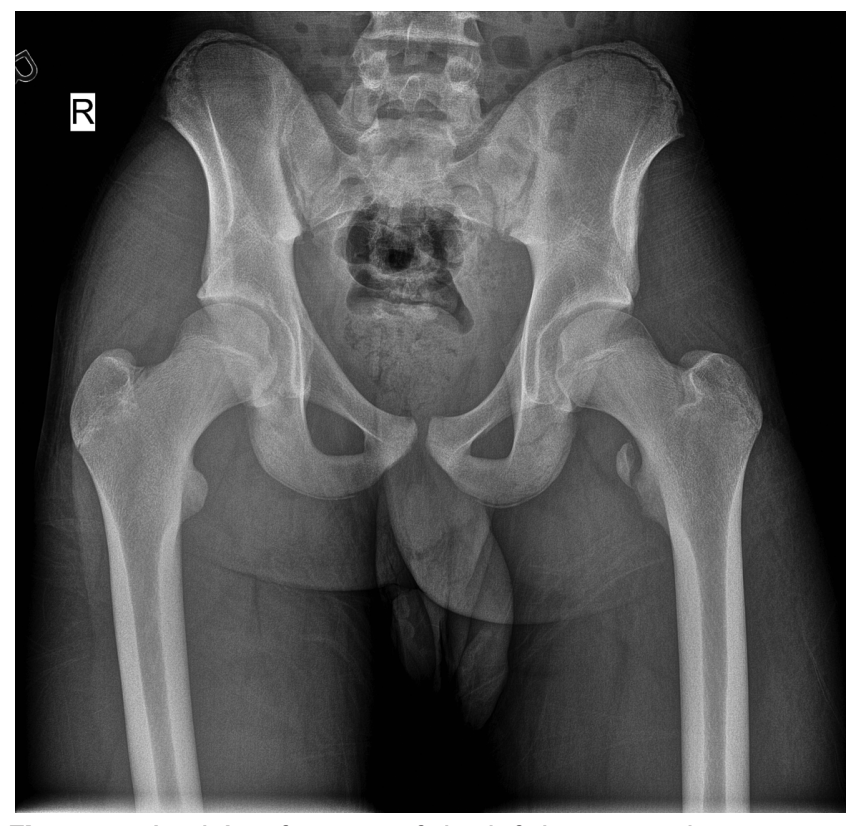

Figure 1. Avulsion fracture of the left lesser trochanter.

are generally produced only by very strong forces, such as those experienced after an impact or a fall.

Mechanisms of injury that typically cause sprains in adults can result in avulsion fractures of the apophyses in children. The pelvic apophyses are bony prominences that arise from secondary ossification centres and serve to anchor the tendons of the hip flexors and extensors. As the insertion of the tendon to the cortex of the bone is stronger than the growth plate, a sudden and forceful muscle contraction can cause disruption of the growth plate. Avulsion fractures arise when the tendon pulls off the bone fragment where it was anchored.

Pelvic avulsion injuries are well described in the orthopedic literature. Six apophyseal sites that can sustain avulsion fractures have been identified in the pelvis. ${ }^{2}$ The more common sites of injury in adolescent athletes are the ischial tuberosity (as a result of excessive pull from the hamstrings), the anterior inferior iliac spine (from the rectus femoris), and the anterior superior iliac spine (from the sartorius). Avulsion fractures of the lesser trochanter, greater trochanter, and iliac crest are less common. ${ }^{3}$

The patient we report presented with pain and limited hip flexion. A positive Ludloff sign-the inability to raise the thigh when in a sitting positionis seen with injuries involving the iliopsoas muscle. Although in adults this suggests tendinitis, in adolescents with acute onset of pain, this may represent an avulsion injury, as in the case presented. ${ }^{4}$ The iliopsoas serves as a major hip flexor. This muscle complex originates from the transverse processes of $\mathrm{T} 12$ to L5 and inserts onto the lesser trochanter-a bony prominence on the medial aspect of the proximal femur. Forceful contraction of the iliopsoas during hip flexion while sprinting likely caused the avulsion fracture of the lesser trochanter sustained by our patient.

Radiographs are an important tool in the assessment of hip pain in adolescents. Although the treatment of apophyseal injuries rarely requires surgical intervention, ${ }^{3}$ other injury patterns may cause hip pain and have poor prognoses if not identified and treated in time. Slipped capital femoral epiphysis (SCFE) is one such hip disorder. SCFE is the posterior slippage of the proximal femoral epiphysis. It is the most common hip disorder of adolescence. Patients with SCFE are typically overweight, and the pain on presentation can vary and has been reported anywhere from the groin to the medial aspect of the knee. SCFE can have serious complications such as avascular necrosis of the femoral head, functional disability, and osteoarthritis. Legg-Calvé-Perthes disease, although usually seen in the first decade of life, should also be considered in the differential diagnosis of pediatric hip pain. This condition involves avascular necrosis of the femoral head, resulting in impaired development of the hip joint. Orthopedic consultation and follow-up are required for both hip disorders. ${ }^{5}$

Radiographs may appear normal in avulsion fractures of unossified bone. If the diagnosis is suspected, further assessment with ultrasonography or magnetic resonance imaging may be helpful. ${ }^{\circ}$

The management of an avulsion fracture of the lesser trochanter is usually nonoperative and supportive. ${ }^{1,3,7-9}$ Rest and nonsteroidal antiinflammatory medications are typically sufficient. Non-weight bearing is recommended. Return to normal activity should be gradual as union is estimated to occur after 6 weeks. ${ }^{3}$ Treatment with immobilization in a spica cast has been used but has been found unnecessary given the satisfactory results obtained with symptomatic management. ${ }^{3}$ Surgical repair with open reduction and internal fixation has been reported in cases where conservative management has resulted in nonunion. ${ }^{10}$

\section{CONCLUSION}

The approach to the evaluation of musculoskeletal injuries in adolescents requires consideration of the 
peculiarities of the immature skeleton. Children can sustain avulsion fractures from mechanisms that typically cause sprains in adults. Radiographs are not only helpful in confirming the diagnosis but can also aid in ruling out more serious hip disorders of childhood.

Competing interests: None declared.

\section{REFERENCES}

1. Amaral JF. Thoracoabdominal injuries in the athlete. Clin Sports Med 1997;16:739-53, doi:10.1016/S0278-5919(05) 70051-X.

2. Fernbach SK, Wilkinson RH. Avulsion injuries of the pelvis and proximal femur. A7R Am $\mathcal{F}$ Roentgenol 1981;137:581-4.

3. Dimon JH. Isolated fractures of the lesser trochanter of the femur. Clin Orthop 1972;82:144-8.
4. Johnston CA, Wiley JP, Lindsay DM, Wiseman DA. Iliopsoas bursitis and tendinitis. A review. Sports Med 1998; 25:271-83, doi:10.2165/00007256-199825040-00005.

5. Kocher MS, Tucker R. Pediatric athletic hip disorders. Clin Sports Med 2006;25:241-53, doi:10.1016/j.csm.2006.01.001.

6. Pisacano RM, Miller TT. Comparing sonography with $M R$ imaging of apophyseal injuries of the pelvis in four boys. $A 7 R$ Am 7 Roentgenol 2003;181:223-30.

7. Sanders TG, Zlatkin MB. Avulsion injuries of the pelvis. Semin Musculoskelet Radiol 2008;12:42-53, doi:10.1055/s-2008-1067936.

8. Bertin KC, Horstman J, Colemen SS. Isolated fracture of the lesser trochanter in adults: an initial manifestation of metastatic malignant disease. 7 Bone foint Surg Am 1984; 66:770-3.

9. Sundar M, Carty H. Avulsion fractures of the pelvis in children: a report of 32 fractures and their outcome. Skel Radiol 1994;23:85-90, doi:10.1007/BF00563198.

10. Fasting OJ. Avulsion of the lesser trochanter. Arch Orthop Trauma Surg 1978;91:81-3, doi:10.1007/BF00383646. 